\title{
Effect of lonizing Beta Radiation on the Strength of Bonded Joints of Polycarbonate
}

\author{
Martin Bednarik $^{1, a}$, David Manas ${ }^{1, b}$, Miroslav Manas ${ }^{2, ~ c}$, Michal Stanek ${ }^{1, d}$, Jan \\ Navratil $^{1, e}$, Ales Mizera $^{1, f}$ \\ ${ }^{1}$ Department of Production Engineering, Tomas Bata University in Zlin, nám. T. G. Masaryka 275, \\ 76272 Zlin, Czech Republic \\ ${ }^{2}$ Faculty of Applied Informatics, Tomas Bata University in Zlin, Nad Stráněmi 4511, 76005 Zlin, \\ Czech Republic \\ ambednarik@ft.utb.cz (Corresponding Author), ${ }^{b} d m a n a s @ f t . u t b . c z,{ }^{c}$ manas@fai.utb.cz, \\ dstanek@ft.utb.cz, ${ }^{\mathrm{d}} \mathrm{j} 1$ navratil@ft.utb.cz, ${ }^{\mathrm{f}}$ mizera@ft.utb.cz
}

Keywords: bonded joints, surface energy, adhesions, ionizing beta radiation, polycarbonate

\begin{abstract}
In this study there was found that ionizing beta radiation increased the strength of bonded joints and improved the adhesion properties of polycarbonate (PC). Generally, for the formation of quality bonded joint it is important to wet the adhesive bonding surface well. Wettability is characterized by the contact angle of wetting. The liquid has to have a lower surface tension than the solid in order to be able to wet the solid substance. The measurement results indicated that ionizing beta radiation was a very effective tool for the improvement of adhesive properties and increased the strength of bonded joints of polycarbonate. Bonded surfaces with ionizing beta radiation doses of $0,33,66$, and $99 \mathrm{kGy}$ were irradiated. The best results were achieved by irradiation at dose of $66 \mathrm{kGy}$ by which the highest surface energy and the highest strength of bonded joints of PC were achieved. The strength of bonded joints after irradiation was increased up to $50 \%$ compared to untreated material. A similar trend was observed even for contact angle of wetting and surface energy.
\end{abstract}

\section{Introduction}

Bonding has experienced tremendous expansion in the field of joining materials in the last years. Because of that expansion bonding is classed as new techniques even when it is in fact very old. Bonding is the surface-to-surface joining of similar or dissimilar materials using a substance which usually is of a different type, and which adheres to the surface of the two adherents to be joined, transferring the forces from one adherent to the other [1,2].

In comparison with conventional joining methods (riveting, welding and screwing) bonding provides a new combination of options and it allows obtaining special shapes and properties which cannot be created by conventional methods of coupling [3]. Joining materials using adhesive joints offers several benefits, but also limiting factors if compared with using mechanical joints. To decide about the type of coupling it is necessary to consider the advantages and disadvantages of bonding in comparison with traditional joining technique $[3,4,5]$.

The advantage of bonded joints is that we can connect the same and dissimilar materials and do not take into account the thickness. Application of adhesives does not undermine the coherence of the connect parts and watertight and gastight joints may be prepared. It does not disturb profile or aesthetic appearance of bonded file and does not increase its weight. Joints can be transparent or colored and it is possible to achieve their high strength.

Adhesive bonding has also several technological disadvantages, in comparison with mechanical joints. The disadvantages of bonded joints are the requirements for planeness and cleanness of surface to be bonded and sensitivity to peel stress. Special surface treatments are required for bonded materials with poor adhesion properties and maximum bond strength is reached after the certain time $[3,4,5]$. 


\section{Experimental}

Materials. For this experiment polycarbonate PC Makrolon AL 2647 was used. Polycarbonate is characterized by the following properties:

- Low density and high strength, stiffness and hardness over the range from -150 to $+135^{\circ} \mathrm{C}$ unreinforced and from -150 to $+145^{\circ} \mathrm{C}$ when reinforced,

- crystal clear transparency, high surface gloss,

- can be colored in all important shades, transparent, translucent or opaque with great depth of color,

- good electrical insulation properties which are not impaired by moisture,

- high resistance to high energy radiation,

- self-extinguishing after removal of the ignition source [6].

The samples were made using the injection molding technology on the injection molding machine Arburg Allrounder 420C. The samples had the shape and dimensions according to the CSN EN ISO $527-2$. Before bonding surfaces of samples ionization beta radiation were irradiated with doses of 0,33, 66, and $99 \mathrm{kGy}$ at Beta - Gamma Service GmbH \& Co. KG, Germany.

Surface treatment by beta radiation. Ionizing radiation is radiation at which quanta have a high energy and can knock out electrons from atomic shell and ionize the substance. Electrically neutral atoms become positive and negative ions [7]. The cross - linking level can be adjusted by irradiation dosage and often by means of a cross - linking booster. The main difference between $\beta$ and $\gamma$ - rays is in their different abilities of penetrating the irradiated material. Gamma rays have a high penetration capacity. The penetration capacity of electron rays depends on the energy of the accelerated electrons. Due to accelerated electron the required dose may be applied for seconds, whereas several hours are required on the $\gamma$-radiation plant. The electron accelerators operate on the principle of the Braun tube, whereby a hot cathode is heated in vacuum to such a degree that electrons are released $[8,9]$.

Wetting contact angle measurements. The angle of contact was measured by using the sessile drop (Fig. 1) and surface energy was determined by OWRK method (Owens - Wendt - Rabel Kaelble method) [10].

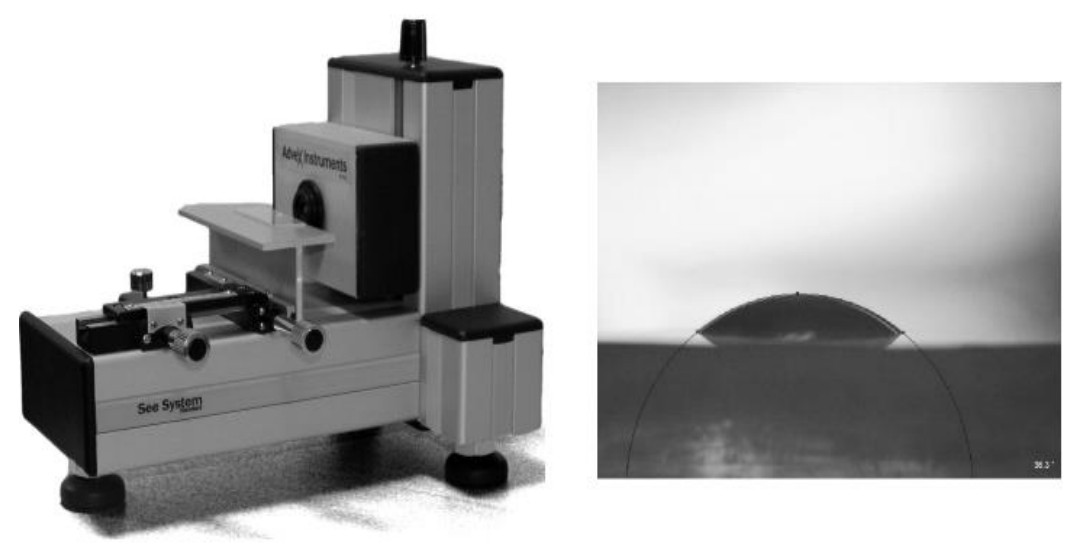

Fig. 1. Surface Energy Evaluation System (See System)

The liquids water, glycerol and ethylene glycol with known $\gamma^{\mathrm{p}}$ (polar component) and $\gamma^{\mathrm{d}}$ (dispersive component) were used for calculating the surface energy of PC.

Table 1. Surface energy of liquids

\begin{tabular}{l|c|c|c}
\hline Liquid & $\gamma_{1}\left(\mathrm{~mJ} / \mathrm{m}^{2}\right)$ & $\gamma_{1}^{\mathrm{d}}\left(\mathrm{mJ} / \mathrm{m}^{2}\right)$ & $\gamma_{1}^{\mathrm{p}}\left(\mathrm{mJ} / \mathrm{m}^{2}\right)$ \\
\hline Distilled water & 72.8 & 21.8 & 51.0 \\
Glycerol & 64.0 & 34.0 & 30.0 \\
Ethylene glycol & 48.0 & 29.0 & 19.0 \\
\hline
\end{tabular}


The height (h) and radius ( $\mathrm{r}$ ) of the liquids were measured by using microscope and the contact angle was calculated using the following equation:

$$
\text { Contact angle }(\theta)=\frac{\sin ^{-1}(2 r h)}{\left(r^{2}+h^{2}\right)}
$$

The polar and dispersive components of the surface energy of the polymer surface were calculated using methods OWRK.

$$
\frac{(1+\cos \theta) \gamma_{1}}{2 \sqrt{\gamma_{1}^{\mathrm{d}}}}=\sqrt{\gamma_{\mathrm{s}}^{\mathrm{p}}} \sqrt{\frac{\gamma_{1}^{\mathrm{p}}}{\gamma_{1}^{\mathrm{d}}}}+\sqrt{\gamma_{\mathrm{s}}^{\mathrm{d}}},
$$

where $\theta$ is the contact angle of testing liquids, $\gamma_{1}$ is the liquid surface energy, and $\gamma_{1}^{\mathrm{p}}$ and $\gamma_{1}^{\mathrm{d}}$ are the polar and dispersive components of the test liquids. The values of polar and dispersive components of testing liquids are given in Table $1[3,10]$. Similarly, the solid - surface energy $\left(\gamma_{\mathrm{s}}\right)$ is expressed in terms of its polar and dispersive components

$$
\gamma_{\mathrm{s}}=\gamma_{\mathrm{s}}^{\mathrm{p}}+\gamma_{\mathrm{s}}^{\mathrm{d}}
$$

Testing the strength of bonded joints. After sample preparation (production and irradiation) contact angles were measured and surface energy was calculated. Then the samples were bonded and their strength was measured. For testing the strength of bonded joints there was used a tensile test on the test machine Zwick 1456. Test conditions were according to the CSN EN ISO $527-1$ and CSN EN ISO 527 - 2. Speed was $10 \mathrm{~mm} / \mathrm{min}$ and evaluation software was Test Expert Standard.

\section{Results and discussion}

Contact Angle and Surface Energy. The variation in contact angle of PC for different doses of radiation and for different test liquids is shown in Figure 2. It shows that the contact angle on the untreated surface is $79.6^{\circ}, 69.1^{\circ}$, and $55.3^{\circ}$ for distilled water, glycerol, and ethylene glycol, respectively.

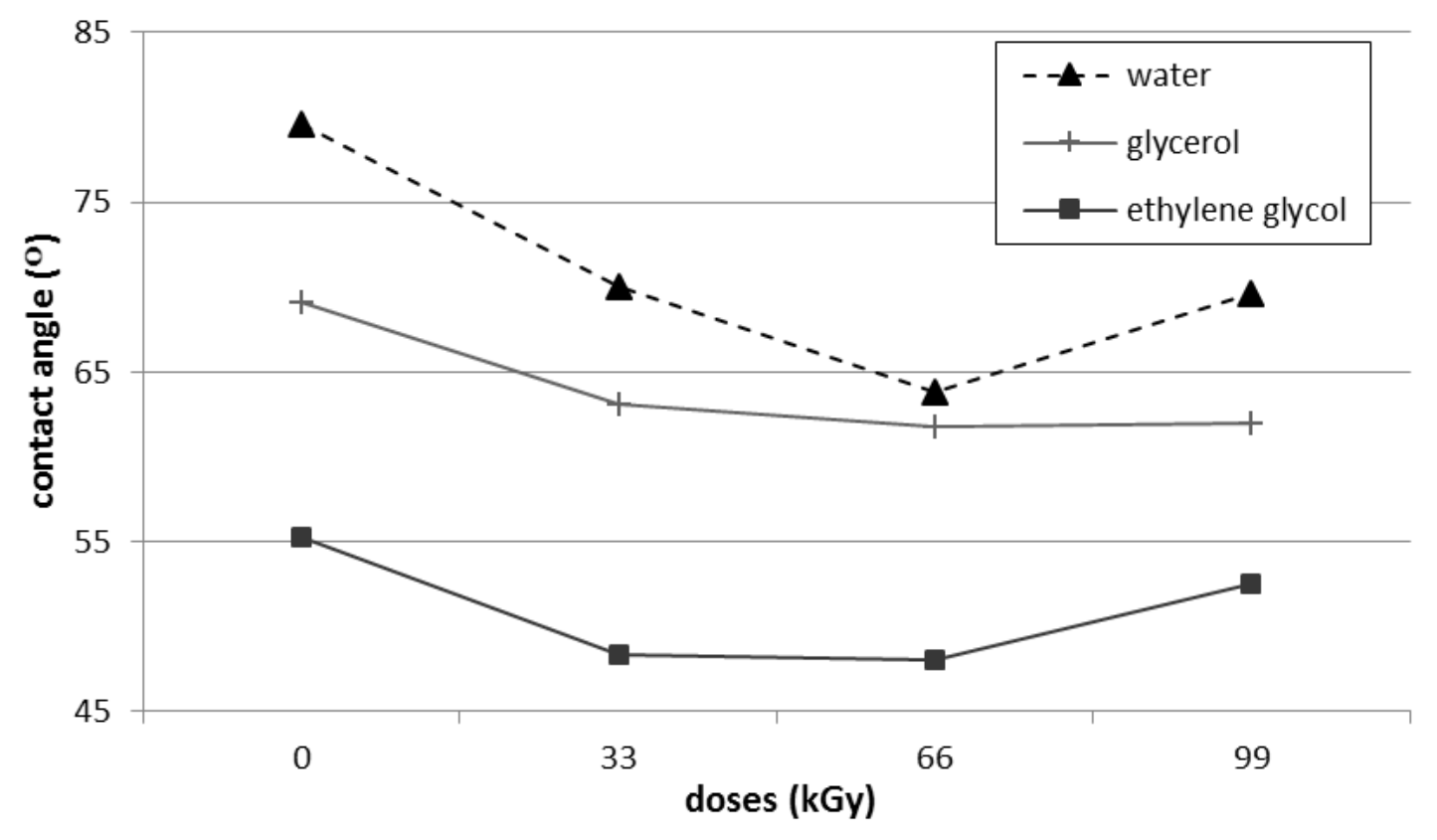

Fig. 2. Variation of contact angle 
The contact angle values considerably reduced after irradiation by a dose of $66 \mathrm{kGy}$ shifting them to lower values $63.8^{\circ}, 61.8^{\circ}$, and $48.0^{\circ}$ for distilled water, glycerol, and ethylene glycol, respectively.

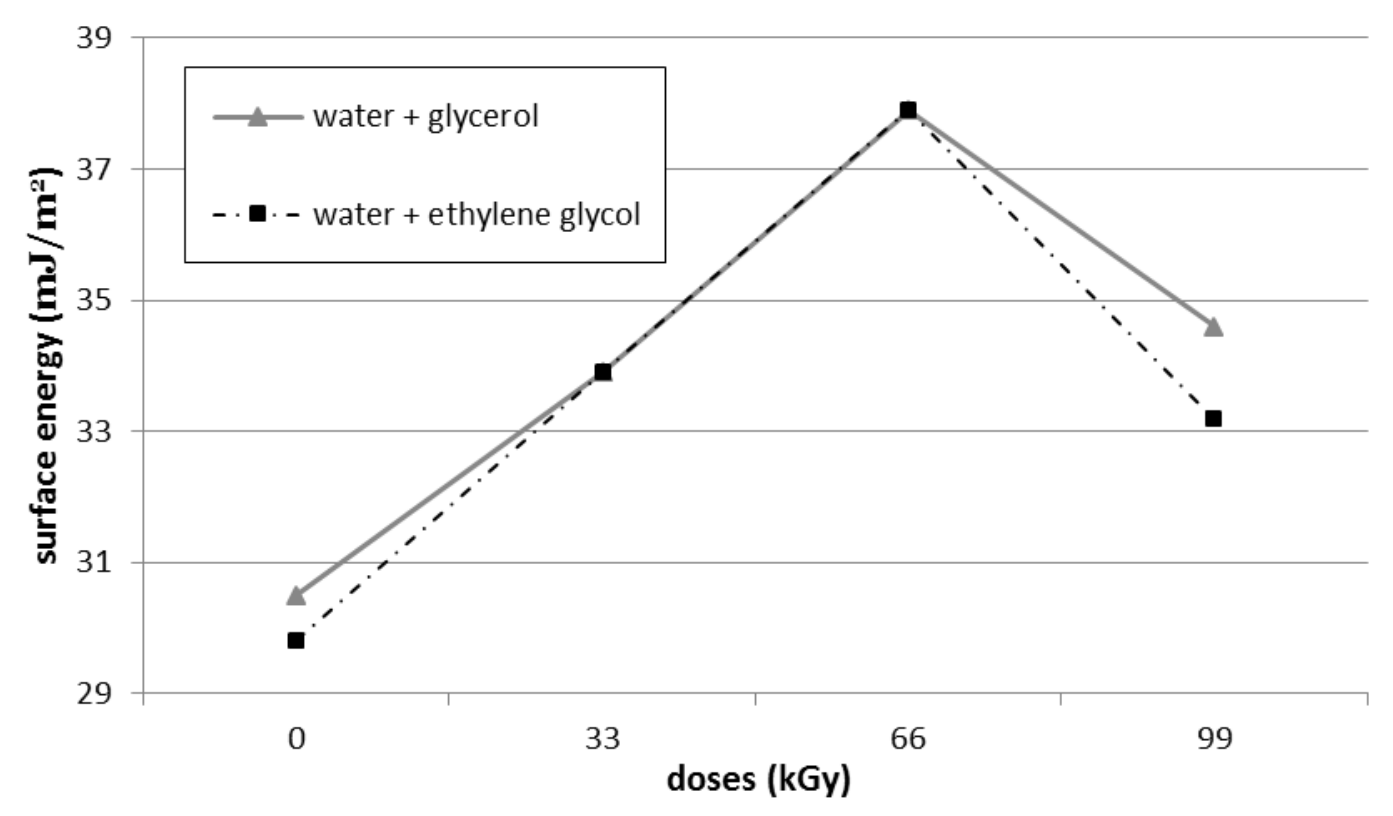

Fig. 3. Variation of surface energy

Figure 3 shows a plot of surface energy $\gamma_{\mathrm{s}}$ from the measured contact angles on the surface of the PC. It shows that surface energy of untreated surface is $30.5 \mathrm{~mJ} / \mathrm{m}^{2}$ and $29.8 \mathrm{~mJ} / \mathrm{m}^{2}$ for water + glycerol and water + ethylene glycol, respectively. Ionization beta radiation increases the surface energy. The surface energy values considerably increased after irradiation by a dose of $66 \mathrm{kGy}$ shifting them to higher values $37.9 \mathrm{~mJ} / \mathrm{m}^{2}$ for water + glycerol and just the same for water + ethylene glycol.

Strength of bonded joints. Strength of bonded joints is characterized by the maximum burdensome stress which endured bonded sample. The highest strength of bonded joints samples have those which were irradiated by a dose of $66 \mathrm{kGy}$.

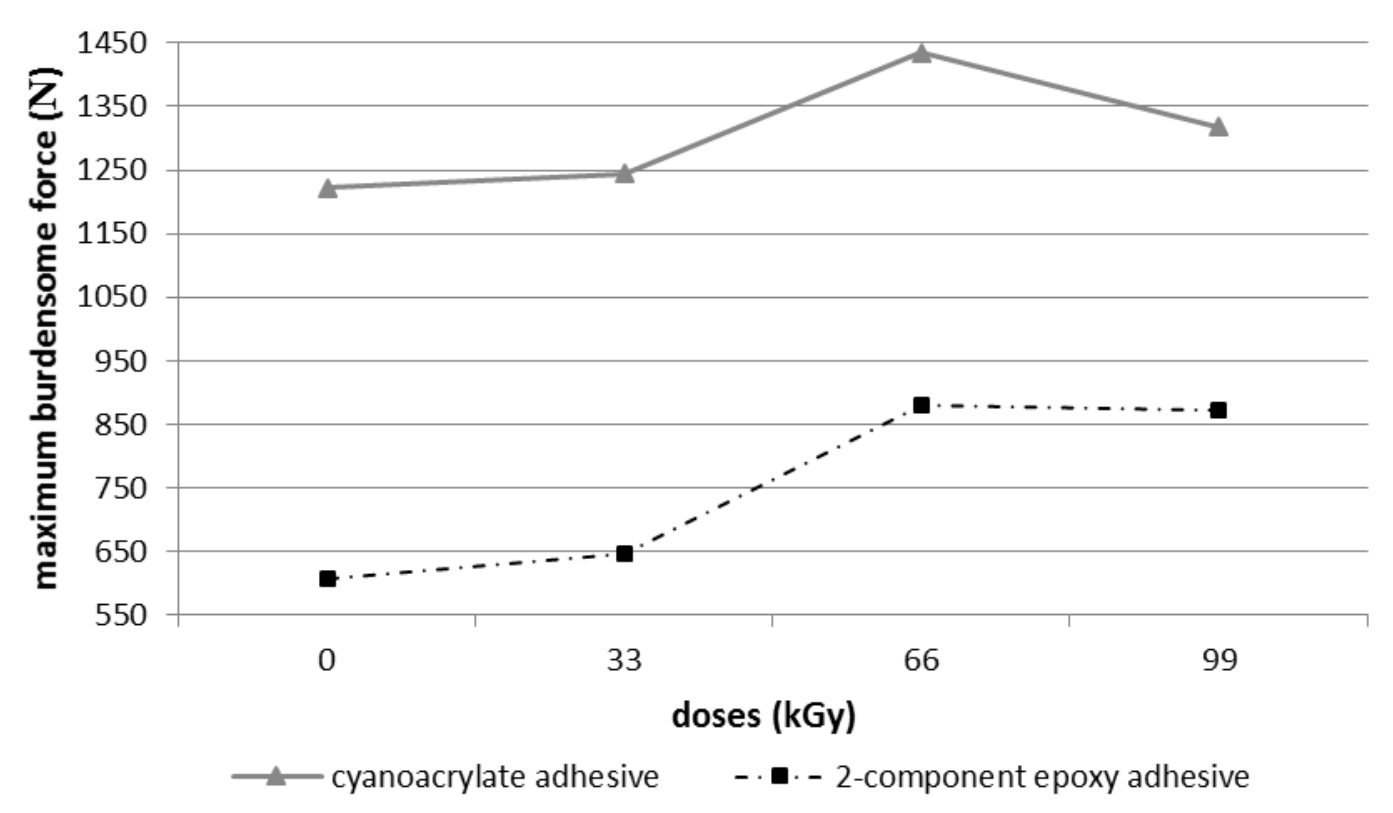

Fig. 4. Variation of strength of bonded joints 
After the irradiation by a dose of $66 \mathrm{kGy}$ strength is increased by $50 \%$ and $20 \%$ for 2 - component epoxy adhesive and cyanoacrylate adhesive, respectively (refer with: Fig. 4).

\section{Summary}

This article describes the effect of beta irradiation on the contact angle of wetting, on the surface energy and on the final strength of bonded joints of polycarbonate. The surface layer of the polymer material such as PC is modified by $\beta$ - radiation with doses of $0,33,66$, and $99 \mathrm{kGy}$. Beta radiation increases the strength of bonded joints of PC and improves its adhesion properties. The best results were achieved by irradiation at a dose of $66 \mathrm{kGy}$ by which the highest surface energy and the highest strength of bonded joints of PC were achieved.

\section{Acknowledgments}

This paper is supported by the internal grant of TBU in Zlin No. IGA/FT/2014/016 funded from the resources of specific university research and by the European Regional Development founder under the project CEBIA-Tech No. CZ.1.05/2.1.00/03.0089.

\section{References}

[1] W. Brockmann et al.: Adhesive Bonding: Materials, Applications and Technology (WILEYVCH, Weinheim 2009).

[2] G. Habenicht: Kleben: Grundlagen, Technologien, Anwendungen (Springer, Berlin 2009).

[3] M. Lehocky et al.: Colloids and Surfaces A: Physicochem. Eng. Aspects Vol. 222 (2003), p. 125

[4] B. Lapcikova et al.: J. Appl. Polym. Sci. Vol. 102 (2006), p. 1827

[5] M. Bednarik et al.: International Journal of Mechanics Vol. 8 (2014), p. 10

[6] H. Domininghaus: Plastics for Engineers: Materials, Properties, Applications (Hanser, Munich 1993).

[7] K. Makuuchi and S. Cheng: Radiation processing of polymer materials and its industrial applications (Wiley, Hoboken 2011).

[8] J.G. Drobny: Ionizing radiation and polymers: principles, technology and applications (Elsevier, Oxford 2013).

[9] Z. Holik et al.: Chemicke listy Vol. 105 (2011), p. 269

[10] M. Bednarik et al.: Key Engineering Materials Vol. 586 (2014), p. 79 